\title{
Reconfigurable Multi-Beam Dual-Band Antenna based on Vee Dipoles
}

\author{
Snehalatha L. ${ }^{1}$, Nagendra P. Pathak ${ }^{1}$, and Sanjeev K. Manhas ${ }^{1}$ \\ ${ }^{1}$ Centre of Nanotechnology and Department of Electronics and Communication Engineering, \\ Indian Institute of Technology Roorkee, Uttarakhand, India. \\ *corresponding author, E-mail: snehavinodegmail.com
}

\begin{abstract}
This paper presents a novel antenna configuration to support reconfigurable multi-beam feature with dual-band capability. The proposed design uses four double Vee dipoles with their arms printed on either sides of a substrate and fed through a single coaxial input probe. A single directional beam that can be configured in four directions at quadrature angle in the azimuth (xy-plane) and corresponding dual, triple and quad beams have been obtained by controlling the state of four PIN diodes. A prototype of the proposed antenna has been designed and fabricated. Measured antenna parameters are in good agreement with that of simulated parameters. This highly planar antenna shows similar radiation patterns at both design frequencies enabling concurrent dual-band communication for all fifteen possible beam configurations.
\end{abstract}

\section{Introduction}

Reconfigurability has become a highly desirable feature in modern wireless communication systems. Antennas with reconfigurable capability in terms of frequency, radiation pattern and polarization have been studied extensively in the past fifteen years for various applications. Advantages of having reconfigurable antennas are numerous: increase in channel capacity, reduction in co-channel interference and multipath fading, enhanced spectral efficiency, better wireless security and reduced power consumption [1]. Conventionally, pattern reconfigurability is achieved by using phased antenna arrays, which are large, complex and costly assemblies. Many applications do not require such complexity and a simpler/cheaper system is necessary to adapt. An antenna array with multi-port controlled beam switching is reported in [2] for multiple-input-multipleoutput (MIMO) applications. A multi-beam antenna composed of nine vertical monopole antennas embedded in a dielectric cylinder mounted on a ground plane is presented in [3]. In [4], director-reflector pairs are used to achieve beam switching via PIN diodes. Such antennas with vertical standing features on the substrate lead to packaging concerns. Planar antenna having low profile, low cost and ease of integration is an attractive alternative.

One of the techniques employed in the design of planar reconfigurable antenna is the usage of parasitic elements. Planar parasitic antennas with reconfigurable pattern are realized using PIN diodes in [5-7]. Dual-band capability along with pattern reconfigurability is necessary to support modern multi-band and multi-functional communication systems. Eventhough many papers are available on dual-band frequency reconfigurable antennas, only a few papers can be found on dual-band pattern reconfigurable antennas that support planar integration. A dual-band reconfigurable frequency-selective reflector based antenna is designed in [8]. Another design reported in [9] is based on parasitic arrays for MIMO applications. However, the non-planar arrangement of antenna elements makes these unsuitable for planar implementation. A dualport diversity dual-band antenna is studied in [10]. A dualband Yagi-Uda antenna is reported in [11] using complementary split ring resonators. However, the radiation patterns are not aligned in the same direction for the two design frequencies making it unsuitable for concurrent communication with the same receiver. To overcome these issues, a dual-band antenna based on printed Vee dipoles is proposed in this paper. Many proposals on antenna based on dipoles are available in the literature. A dual-band antenna based on printed dipoles is presented in [12]. Antennas based on dipoles with beam switching feature are reported in [13-15], but for single band applications. In addition to reconfigurable and dual-band capability, multi-beam feature is also necessary to enable concurrent communication with multiple users or to improve the link quality of wireless communication systems. The design of an antenna that has a planar structure supporting reconfigurable radiation pattern with simultaneous multi-beam configuration at more than one frequency is a task yet to accomplish. Such antennas are anticipated to be important for future concurrent communication systems. The antenna proposed in this paper uses four PIN diodes to connect any of the four double Vee dipoles to realize similar radiation beams at two frequency bands simultaneously. The truth table for different azimuth pattern configurations supported by the antenna is given in Table 1. The radiation patterns for all these states are confirmed by a series of pattern measurements at both frequencies. The proposed planar antenna thus provides an option to choose any one of the four single beam, six dual beam, four triple beam or one quad beam patterns in the azimuth plane. Moreover, similar 
radiation patterns are obtained at two frequencies simultaneously making the antenna a good choice for use in concurrent diversity applications.

Table 1: Beam switching configurations.

\begin{tabular}{llllll}
\hline Case & sw1 & sw2 & sw3 & sw4 & Beam Direction $(\phi)$ \\
\hline 1 & 1 & 0 & 0 & 0 & $90^{\circ}$ \\
2 & 0 & 1 & 0 & 0 & $0^{\circ}$ \\
3 & 0 & 0 & 1 & 0 & $270^{\circ}$ \\
4 & 0 & 0 & 0 & 1 & $180^{\circ}$ \\
5 & 1 & 1 & 0 & 0 & $90^{\circ}, 0^{\circ}$ \\
6 & 1 & 0 & 0 & 1 & $90^{\circ}, 180^{\circ}$ \\
7 & 1 & 0 & 1 & 0 & $90^{\circ}, 270^{\circ}$ \\
8 & 0 & 1 & 1 & 0 & $0^{\circ}, 270^{\circ}$ \\
9 & 0 & 1 & 0 & 1 & $0^{\circ}, 180^{\circ}$ \\
10 & 0 & 0 & 1 & 1 & $270^{\circ}, 180^{\circ}$ \\
11 & 1 & 1 & 1 & 0 & $90^{\circ}, 0^{\circ}, 270^{\circ}$ \\
12 & 1 & 1 & 0 & 1 & $90^{\circ}, 0^{\circ}, 180^{\circ}$ \\
13 & 1 & 0 & 1 & 1 & $90^{\circ}, 180^{\circ}, 270^{\circ}$ \\
14 & 0 & 1 & 1 & 1 & $0^{\circ}, 180^{\circ}, 270^{\circ}$ \\
15 & 1 & 1 & 1 & 1 & $0^{\circ}, 90^{\circ}, 180^{\circ}, 270^{\circ}$ \\
\hline
\end{tabular}

\section{Antenna Design}

Vee dipoles are characterized by increase in directivity and reduced sidelobes as compared to their linear counterparts. Symmetrical Vee antenna having a specified arm length can have maximum directivity for an optimum Vee angle [16] The proposed multi-beam antenna is composed of four identical elements arranged symmetrically around the centre input probe as shown in Fig. 1. Each element consists of a pair of Vee dipoles of which the inner Vee dipole decides the lower frequency whereas the outer dipole determines the

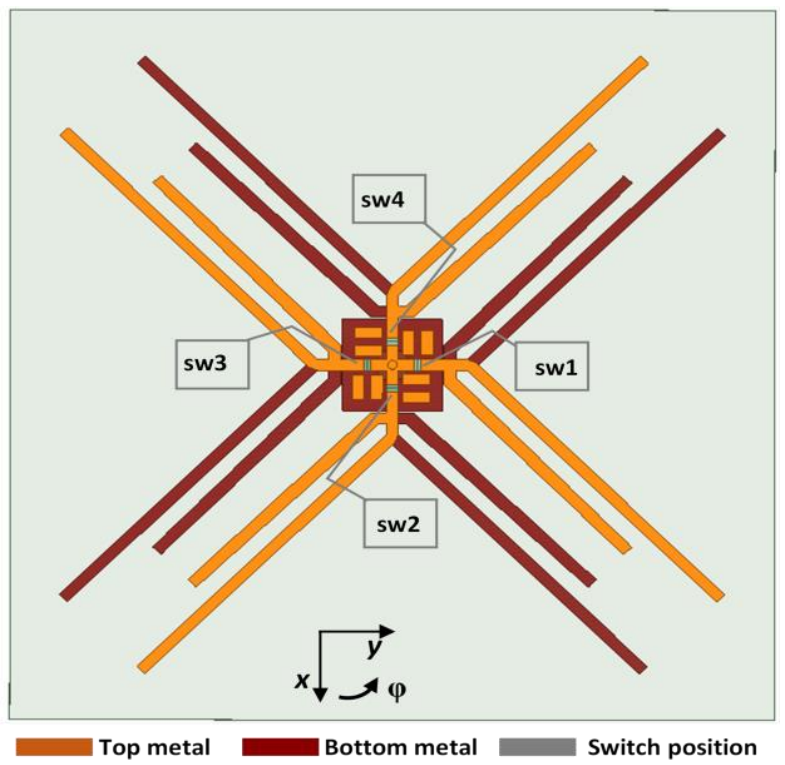

Figure 1: Geometry of the antenna. higher frequency band. The symmetrical Vee dipoles are chosen to have unidirectional radiation pattern in the direction of the Vee opening. Each dipole has two identical double arms that are printed on either sides of the substrate. A single $50 \Omega$ SMA connector fed from the other side of the substrate is connected to four parallel-strip feedlines. Each of these feedlines is connected to the antenna element through a switch (sw1-sw4) realized using PIN diode, BAP64-02. By controlling the combination of PIN diodes that are turned $\mathrm{ON}$ at any instant, single, dual, triple or quad beams are generated.

The bias circuit for the PIN diode is shown in Fig. 2. The DC supply is applied to the PIN diode through an inductor of $43 \mathrm{nH}$ to isolate the power supply. A capacitor of $2.2 \mathrm{pF}$ is used to bypass any AC signals at the supply side.

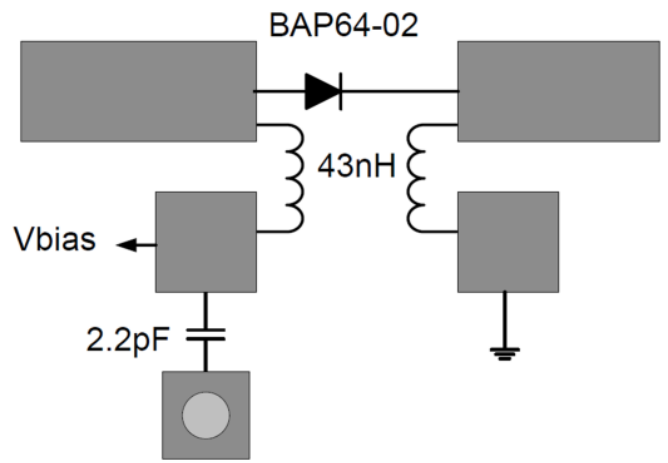

Figure 2: Biasing circuit for PIN diode.

For the design of dual-band antenna, the length of the Vee dipole arms is first determined. One full wavelength is chosen as a compromise between the size and directivity. Once the length $\left(\mathrm{L}_{1}\right)$ of the inner dipole arm is fixed as $49 \mathrm{~mm}$ corresponding to a frequency of $3.3 \mathrm{GHz}$ $\left(f_{1}\right)$, the length of parallel strip feed is designed for impedance matching [17]. The input impedance of the Vee

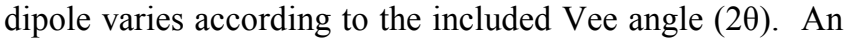
angle of $90^{\circ}$ has been chosen which provides an impedance value close to $50 \Omega$, thus simplifying the feed network. The length of outer dipole $\left(\mathrm{L}_{2}\right)$ is chosen as $39 \mathrm{~mm}$ for the second band's centre frequency of $4.2 \mathrm{GHz}\left(f_{2}\right)$. The length of the parallel feedlines is further characterized to achieve good impedance matching for both frequency bands.

The design of the antenna has been simulated in ANSYS HFSS 17.1. The substrate having a relative permittivity of 4.4 and thickness of $0.8 \mathrm{~mm}$ is used in the design. The length of inner dipole, $\mathrm{L}_{1}$ and the length of outer dipole, $\mathrm{L}_{2}$ have been optimized to $46 \mathrm{~mm}$ and $36 \mathrm{~mm}$ owing to the coupling between the double Vee arms as well as the adjacent antenna elements. Switches have been simulated by modeling PIN diodes as two lumped RLC components in series. The ON state of PIN diode is modeled as two parallel RLC lumped components, $\mathrm{L}_{\mathrm{s}}$ and $\mathrm{R}_{\mathrm{s}}$ connected in series. The OFF state of PIN diode is modeled as the series combination of two parallel RLC lumped components $\mathrm{L}_{s}$ and $\mathrm{C}_{\mathrm{p}}$ parallel $\mathrm{R}_{\mathrm{p}}$. The values of lumped components used for simulation are $\mathrm{L}_{\mathrm{s}}=0.6 \mathrm{nH}, \mathrm{R}_{\mathrm{s}}$ $=2 \Omega$, and $\mathrm{C}_{\mathrm{p}}=0.2 \mathrm{pF}$. The length of the parallel strips has 
been readjusted to compensate for the additional reactance introduced by the PIN diode.

\section{Results and Discussion}

The prototype of the antenna fabricated is shown in Fig. 3. The overall size of the antenna is $10 \times 10 \mathrm{~cm}^{2}$. The return losses for different switching cases listed in Table 1 are plotted in Fig. 4. The centre frequency is observed to be higher in the case where multiple PIN diodes are ON simultaneously. This is attributed to the change in effective length of the antenna when multiple dipole pairs are connected. The measured return loss is better than $10 \mathrm{~dB}$ for all cases. The slight deviations observed in the measured return losses as against the simulated results are due to manufacturing and soldering tolerances. The simulated current density of the antenna when a single switch sw 1 is turned $\mathrm{ON}$ is shown in Fig. 5. The figure shows two distinct current paths for the two design frequencies. Similar current densities have been observed for multiple switches ON

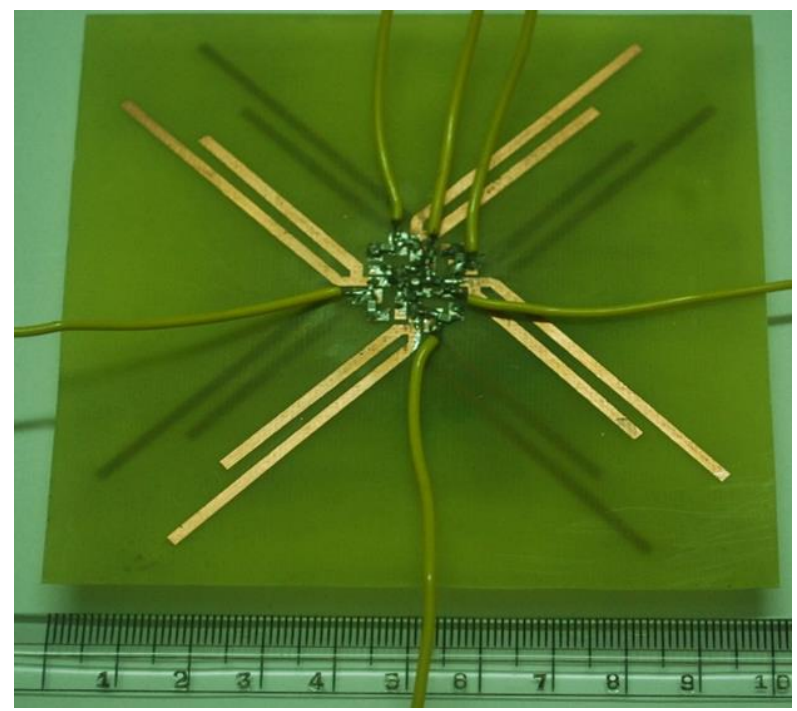

(a)

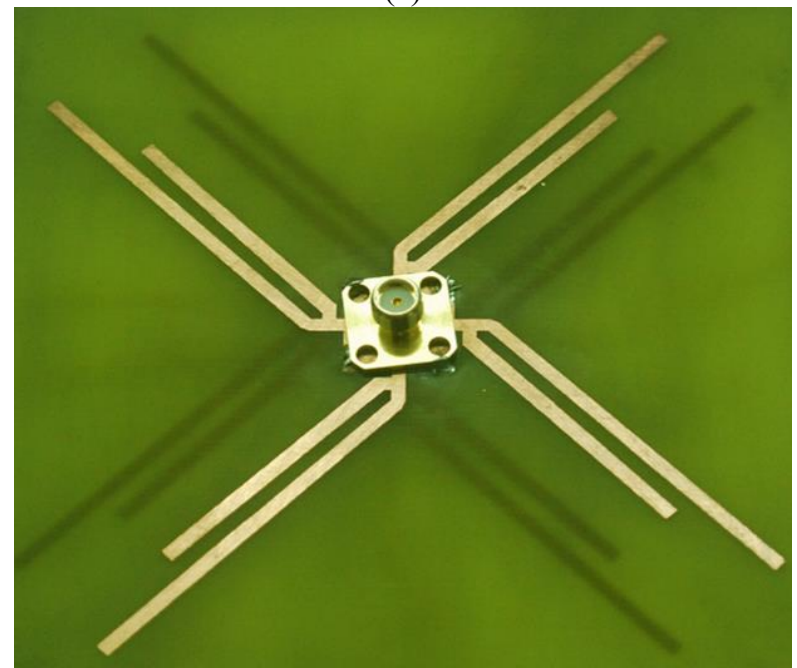

(b)

Figure 3: Photograph of the fabricated antenna (a) front view, (b) rear view. cases too.

The desired radiation patterns according to Table 1 have been obtained according to the four switch combinations.

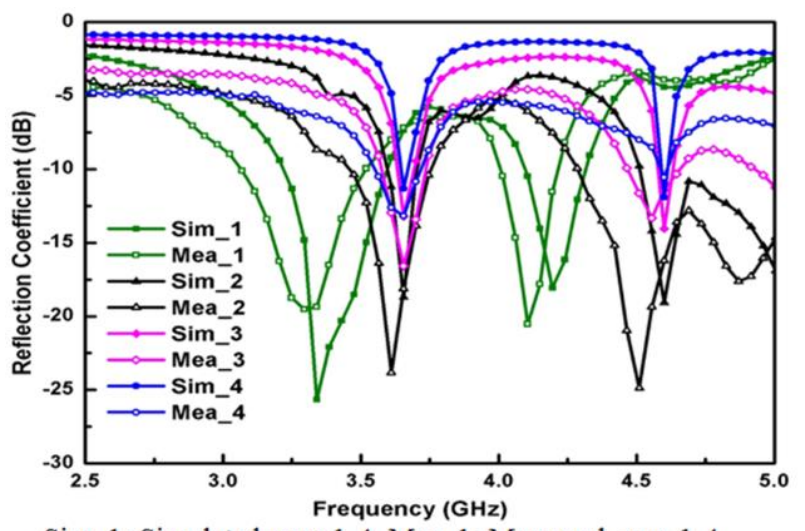

Sim_1: Simulated case 1-4, Mea_1: Measured case 1-4,

Sim_2: Simulated case 5-10, Mea_2: Measured case 5-10,

Sim_3: Simulated case 11-14, Mea_3: Measured case 11-14,

Sim_4: Simulated case 15, Mea_4: Measured case 15

Figure 4: Return loss of the antenna.
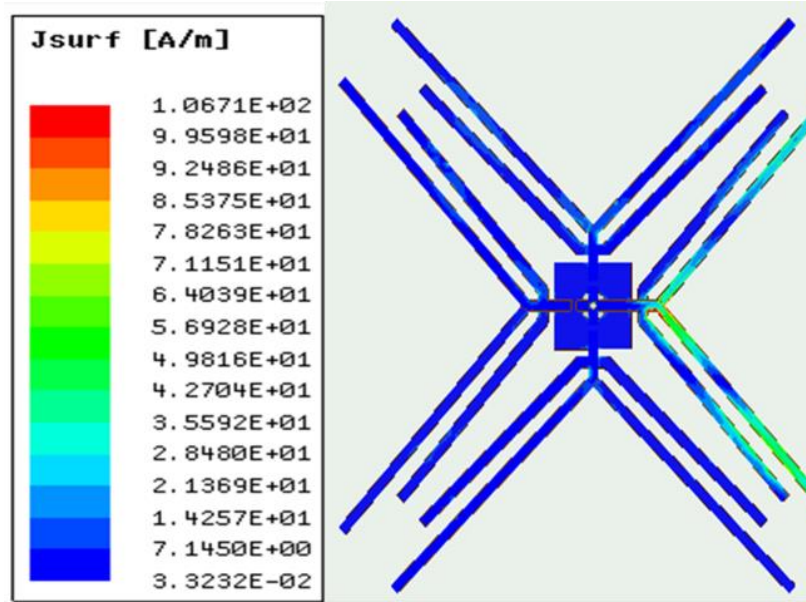

(a)

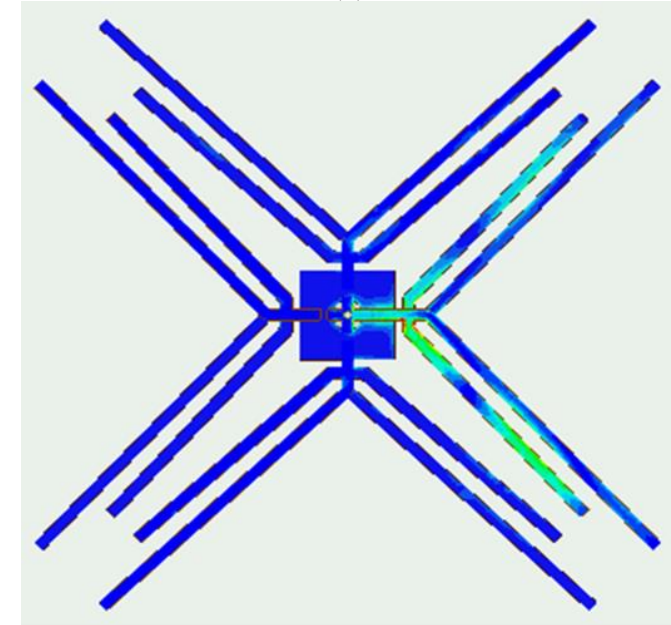

(b)

Figure 5: Simulated current distribution for case 1 (a) $f_{1}$ (b) $f_{2}$. 


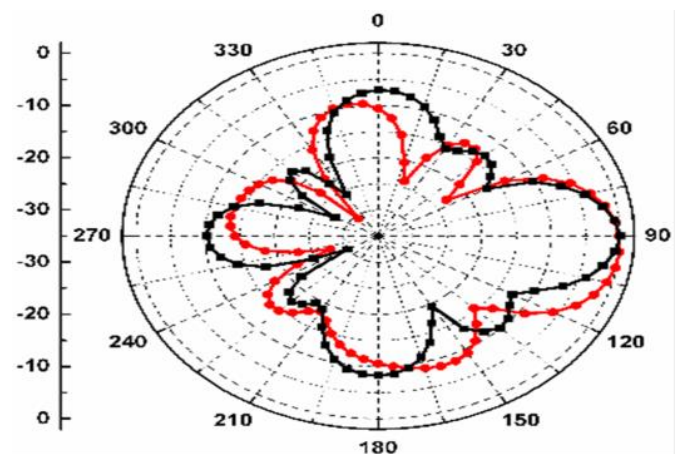

(a)

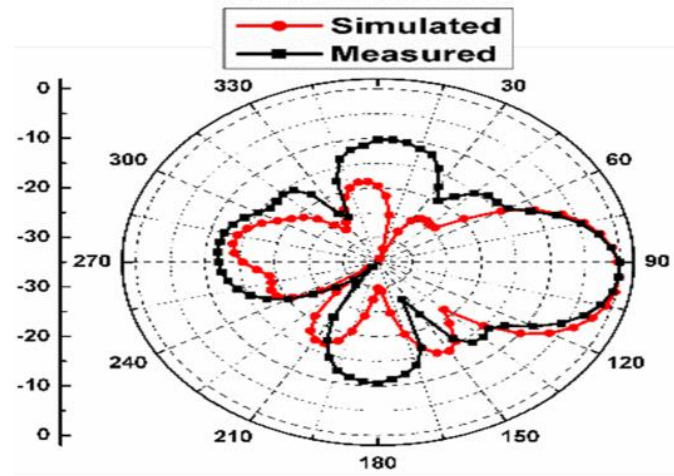

(b)

Figure 6: Radiation pattern in azimuth plane for case 1 (a) $f_{1}$ (b) $f_{2}$.

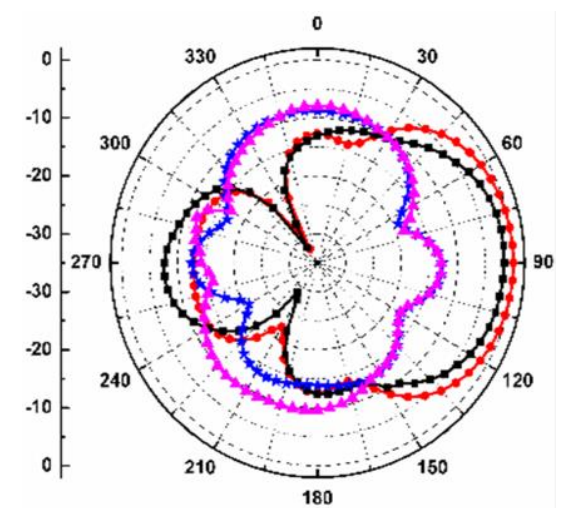

(a)

$\rightarrow$ Simulated YZ plane $\rightarrow$ Measured YZ plane

* Simulated XZ plane $\leftarrow$ Measured XZ plane

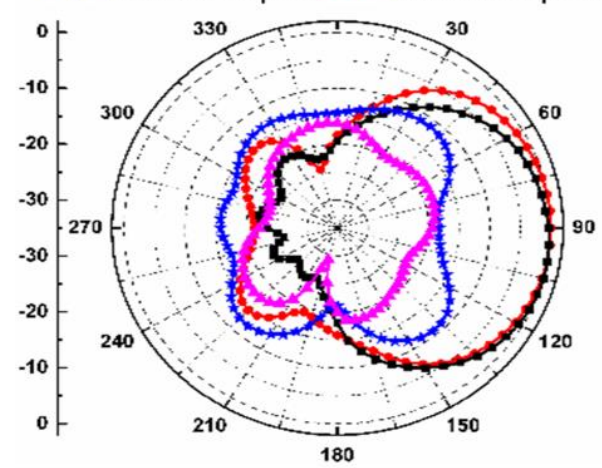

(b)

Figure 7: Radiation pattern in elevation plane for case 1 (a) $f_{1}$ (b) $f_{2}$.
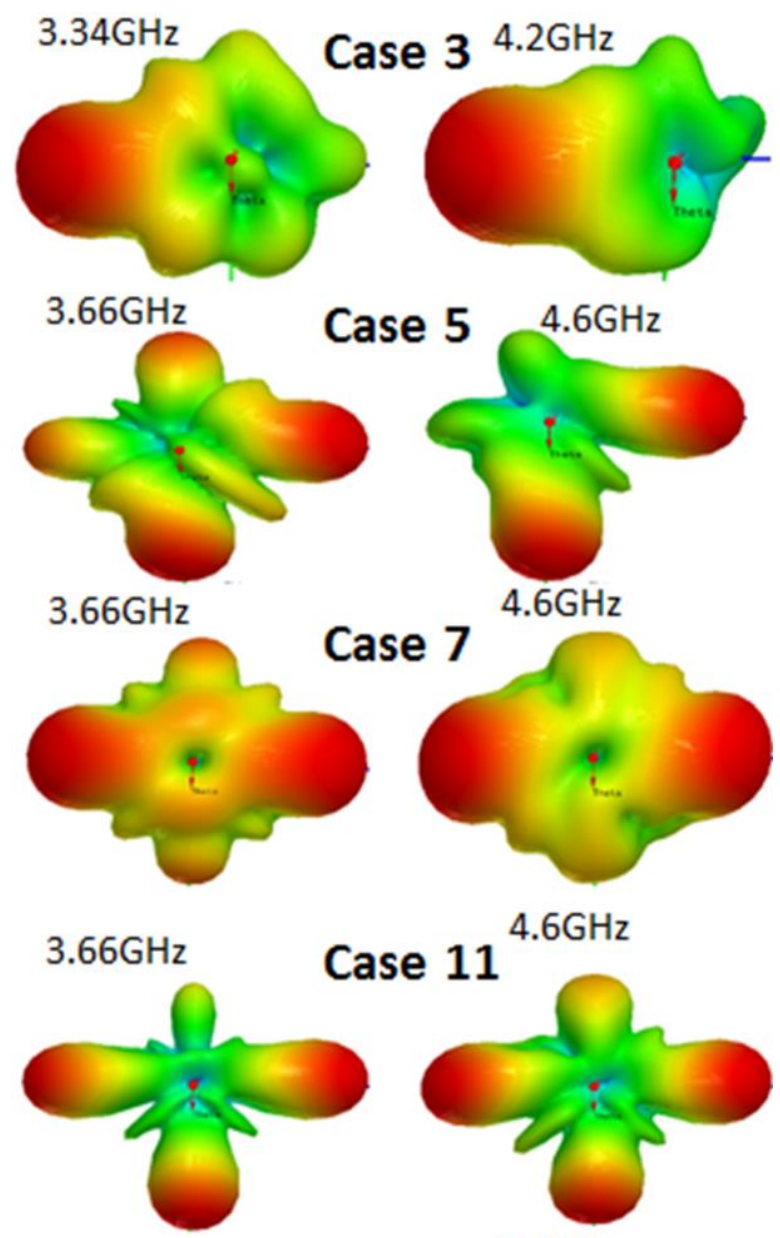

$4.6 \mathrm{GHz}$
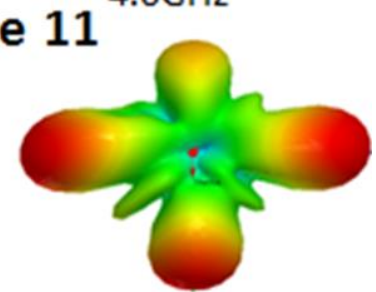

$3.66 \mathrm{GHz}$

4.6 $\mathrm{GHz}$

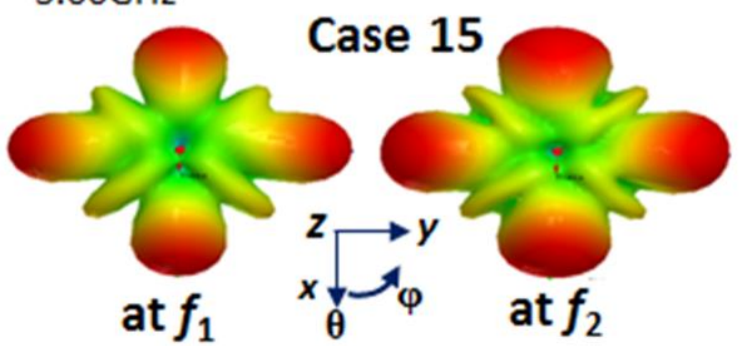

Note: Different scales are used to highlight the direction of max. radiation. Peak values are given in Table 2.

Figure 8: Simulated 3D radiation patterns.

When a single Vee dipole pair is activated, a directional pattern with an average half-power beam-width of $30^{\circ}$ in azimuth is measured as shown in Fig. 6 at $3.3 \mathrm{GHz}\left(f_{1}\right)$ and $4.11 \mathrm{GHz}\left(f_{2}\right)$. Corresponding patterns in elevation plane are given in Fig. 7. When two switches are turned $\mathrm{ON}$ simultaneously, two sets of possible radiation patterns occur: one with peak radiation in opposite directions and another with peak radiation at perpendicular direction in the azimuth plane. The possible categories representative of single and multi-beam cases are illustrated by the $3 \mathrm{D}$ radiation patterns in Fig. 8 at $f_{1}$ and $f_{2}$.

For all the switching configurations, the measured radiation patterns showed good correlation to the simulated 

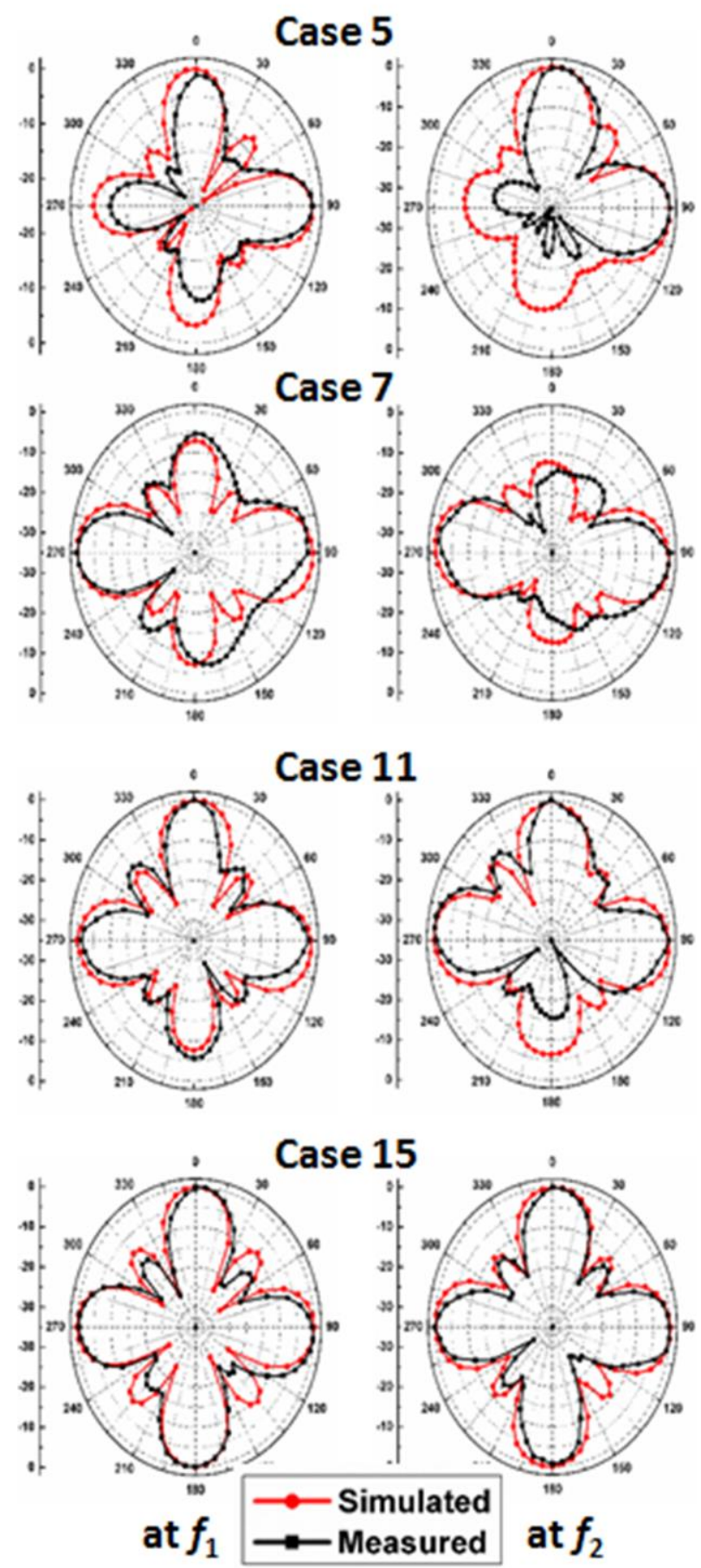

Figure 9: Measured and simulated radiation patterns in azimuth plane.

results as shown in Fig. 9 (azimuth: xy plane) and Fig. 10 (elevation plane). The centre frequencies for various configurations obtained during simulation and measurement are listed in Table 2. The antenna gain, directivity, efficiency and beam-width for the four categories of switch combinations are also consolidated in Table 2. Comparison of the proposed antenna to dual-band pattern diversity antennas already reported is given in Table 3 .

\section{Case 5}
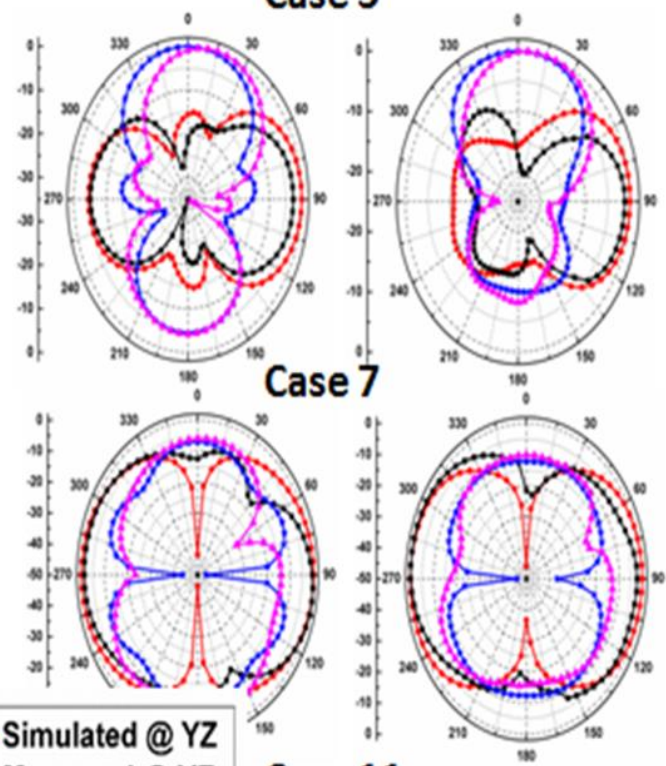

$\rightarrow$ Simulated @ YZ

\section{Ł-Simulated @XZ}

-Measured@XZ
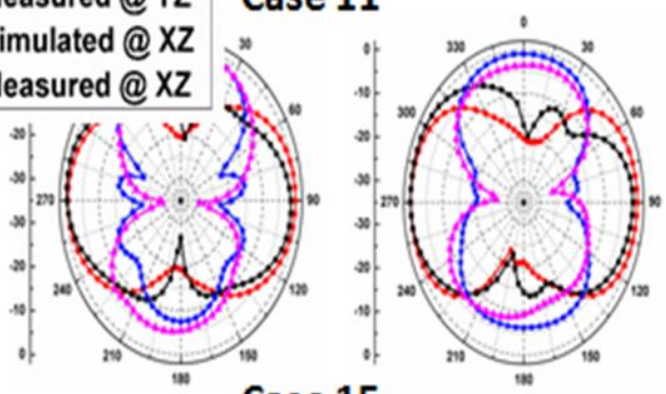

Case 15

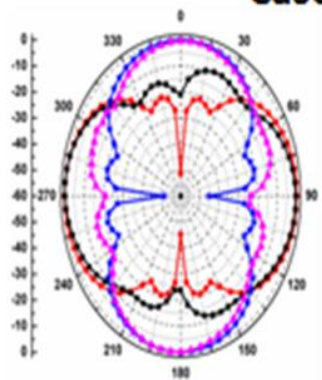

at $f_{1}$

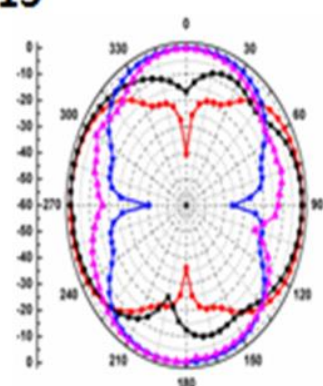

at $f_{2}$
Figure 10: Measured and simulated radiation patterns in elevation plane.

Table 3: Comparison of the proposed antenna with the reported dual-band pattern diversity antennas.

\begin{tabular}{ccccc}
\hline Ref & $\begin{array}{c}\text { Freq } \\
(\mathrm{GHz})\end{array}$ & Switch & $\begin{array}{c}\text { Size } \\
\left(\lambda_{0}\right)\end{array}$ & $\begin{array}{c}\text { No. of } \\
\text { patterns }\end{array}$ \\
\hline$[8]$ & $2.55 / 5.25$ & DPDT & 1249 & 2 \\
$\begin{array}{c}{[9]} \\
\text { This } \\
\text { work }\end{array}$ & $3.4 / 5.8$ & RF Switch & 465 & 9 \\
\hline
\end{tabular}


Table 2 : Antenna parameters for different configurations

\begin{tabular}{|c|c|c|c|c|c|c|c|c|c|}
\hline \multirow{2}{*}{$\begin{array}{c}\text { No. of } \\
\text { switches } \\
\text { ON }\end{array}$} & \multirow{2}{*}{ Freq } & \multicolumn{2}{|c|}{ Centre Freq $(\mathrm{GHz})$} & \multicolumn{2}{|c|}{ Peak gain $(\mathrm{dBi})$} & \multirow{2}{*}{$\begin{array}{l}\text { Simulated } \\
\text { directivity } \\
(\mathrm{dB})\end{array}$} & \multirow{2}{*}{$\begin{array}{c}\text { Simulated } \\
\text { Efficiency } \\
(\%)\end{array}$} & \multicolumn{2}{|c|}{ Beam-width $\left({ }^{O}\right)$} \\
\hline & & Simulated & Measured & Simulated & Measured & & & Simulated & Measured \\
\hline \multirow[t]{2}{*}{1} & $f_{1}$ & 3.34 & 3.30 & 7.82 & 7.23 & 8.61 & 83.79 & 35 & 30 \\
\hline & $f_{2}$ & 4.2 & 4.11 & 7.84 & 7.94 & 9.52 & 76.3 & 30 & 30 \\
\hline \multirow[t]{2}{*}{2} & $f_{1}$ & 3.66 & 3.61 & 6.35 & 6.4 & 7.82 & 73.53 & $30-35$ & $25-30$ \\
\hline & $f_{2}$ & 4.6 & 4.51 & 4.57 & 3.91 & 7.69 & 67.16 & 35 & 30 \\
\hline \multirow[t]{2}{*}{3} & $f_{1}$ & 3.66 & 3.66 & 3.41 & 3.78 & 7.97 & 73.2 & $30-35$ & $20-30$ \\
\hline & $f_{2}$ & 4.6 & 4.56 & 2.83 & 2.14 & 7.15 & 63.1 & 35 & 35 \\
\hline \multirow[t]{2}{*}{4} & $f_{1}$ & 3.66 & 3.66 & 5.2 & 5.38 & 7.48 & 68.5 & 30 & 30 \\
\hline & $f_{2}$ & 4.6 & 4.6 & 2.22 & 2.06 & 6.24 & 61.6 & 30 & $25-30$ \\
\hline
\end{tabular}

\section{Conclusions}

A dual-band antenna based on printed Vee dipoles with multi-beam pattern reconfigurability feature is presented in this paper. The antenna is designed to have centre frequencies at $3.3 \mathrm{GHz}$ and $4.2 \mathrm{GHz}$ for single beam configurations and accordingly the multi-beam configuration showed resonance at $3.66 \mathrm{GHz}$ and $4.6 \mathrm{GHz}$. Measured radiation patterns at both center frequencies validate the switching of patterns accomplished by electronically controlling the state of four PIN diodes. The antenna is shown to have peak radiation in the same directions for both frequencies, enabling concurrent dualband communication between transmitter and receiver. A single substrate antenna without any complex feed circuitry makes this reconfigurable multi-beam antenna highly attractive to integrate into any concurrent dual-band communication system.

\section{References}

[1] C. G. Christodoulou, Y. Tawk, S. A. Lane and S. R. Erwin, Reconfigurable antennas for wireless and space applications, Proc. IEEE 100 : 2250-2261, 2012.

[2] V. A. Nguyen, M. H. Jeong, M. T. Dao and S. O. Park, Four-port beam reconfigurable antenna array for pattern diversity system, IET Microwaves, Antennas \& Propag. $6: 1179-1186,2012$.

[3] J. W. Lu, D. V. Thiel, B. Hanna and S. Saario, Multibeam switched parasitic antenna embedded in dielectric for wireless communications systems, Electronics Lett. $37: 871-872,2001$.

[4] T. Zhang, S. Y. Yao and Y. Wang, Design of radiationpattern-reconfigurable antenna with four beams, IEEE Antennas and Wireless Propag. Lett. 14 : 183-186, 2015.

[5] M. Jusoh, T. Aboufoul, T. Sabapathy, A. Alomainy and M. R. Kamarudin, Pattern-reconfigurable microstrip patch antenna with multidirectional beam for WiMAX application, IEEE Antennas and Wireless Propag. Lett. $13: 860-863,2014$
[6] T. Guo, W. Leng, A. Wang, J. Li and Q. Zhang, A novel planar parasitic array antenna with frequencyand pattern-reconfigurable characteristics, IEEE Antennas and Wireless Propag. Lett. 13 : 1569-1572, 2014.

[7] Y. Cai and Z. Du, A novel pattern reconfigurable antenna array for diversity systems, IEEE Antennas and Wireless Propag. Lett. 8 : 1227-1230, 2009.

[8] C. H. Ko, I. Y. Tarn and S. J. Chung, A compact dualband pattern diversity antenna by dual-band reconfigurable frequency-selective reflectors with a minimum number of switches, IEEE Trans on Antennas and Propag. 61 : 646-654, 2013.

[9] J. K. Ji, Compact dual-band pattern reconfigurable antenna using switched parasitic array, Electronics Lett. $53: 211-212,2017$.

[10] L. Mouffok, A. C. Lepage, J. Sarrazin, and X. Begaud, A compact dual-band dual-port diversity antenna for LTE, Advanced Electromagnetics, 1(1) : 52-56, 2012.

[11] K. Saurav, D. Sarkar, and K. V. Srivastava, A dualband reconfigurable Yagi-Uda antenna with diverse radiation patterns, Applied Physics A 23(7) : 483, 2017.

[12] P. Lindberg, E. Ojefors, Z. Barna, A. Thornell-Pers and A. Rydberg, Dual wideband printed dipole antenna with integrated balun, IET Microwaves, Antennas \& Propag. $1: 707-711,2007$.

[13]Ning Li, Wenhua Chen and Zhenghe Feng, A switched sector beam planar antenna, IEEE Antennas and Propagation Society International Symposium, pp. 230233, 2005

[14] Y. Yao and Z. Feng, Novel switched sector beam planar UWB antenna, Microwave Opt. Technol. Lett. 49 : 1185-1187, 2007.

[15] S. Lalithamma, N. P. Pathak, and S. K. Manhas, Design and Analysis of Vee Dipole Based Reconfigurable Planar Antenna, Progress In Electromagnetics Research Letters 70 : 123-128, 2017.

[16]C. Balanis, Antenna Theory, Analysis, and Design, Wiley, Chapter 10, 2014.

[17] R. Garg, P. Bhartia, I. J. Bahl, A. Ittipiboon, Microstrip Antenna Design Handbook, Artech House, 2001 